\title{
D0I: https://dx.doi.org/10.21879/faeeba2358-0194.2021.v30.n63.p257-269 \\ O MUNDO DO TRABALHO COMO ESPAÇO FORMATIVO FEMININO NAS PRIMEIRAS DÉCADAS DO SÉCULO XX
}

\author{
Karina Regalio Campagnoli* \\ Universidade Estadual de Ponta Grossa \\ https://orcid.org/0000-0002-6068-7073
}

\section{RESUMO}

O objetivo deste artigo é refletir sobre algumas possibilidades de formação feminina durante as três primeiras décadas do século XX, por meio da gradativa inserção das mulheres no universo do trabalho remunerado fora do lar. Optou-se pela metodologia de pesquisa documental com análise qualitativa, investigandose os arquivos do jornal Diário dos Campos, cuja sede encontra-se na cidade de Ponta Grossa, Paraná. Observou-se que, concomitantemente às profissões tradicionalmente compreendidas como adequadas para as mulheres, o gênero feminino também enfrentou os desafios de se inserir em ocupações mais arrojadas para elas neste contexto histórico. Conclui-se que o jornal Diário dos Campos promoveu a circulação de diversas notícias e reportagens que sinalizavam as oportunidades de formação feminina perpassadas pelo mundo do trabalho, possibilitando uma formação não somente profissional, mas também social e humana.

Palavras-chave: formação feminina; educação das mulheres; gênero feminino.

\section{ABSTRACT}

\section{THE WORLD OF WORK AS A WOMEN'S FORMATION SPACE IN THE FIRST DECADES OF THE 20TH CENTURY}

The purpose of this article is to reflect on some possibilities of female education during the first three decades of the 20th century, through the gradual insertion of women in the universe of paid work outside the home. We opted for the documentary research methodology with qualitative analysis, investigating the archives of the newspaper Diário dos Campos, whose headquarters are in the city of Ponta Grossa - Paraná. It was observed that, concomitantly with the professions traditionally understood as suitable for women, the female gender also faced the challenges of entering into more daring occupations for them in this historical context. It is concluded that the newspaper Diário dos Campos promoted the circulation of several news and reports that signaled the opportunities of female education pervaded by the world of work, enabling not only professional but also social and human formation.

Keywords: female formation; women's education; feminine gender.

* Mestre em Educação pela Universidade Estadual de Ponta Grossa (UEPG). Professora do Departamento de Pedagogia da Universidade Estadual de Ponta Grossa (UEPG). Ponta Grossa, Paraná, Brasil. E-mail: karinaregalio@hotmail.com 


\section{RESUMEN \\ EL MUNDO DEL TRABAJO COMO ESPACIO DE FORMACIÓN DE MUJERES EM LAS PRIMERAS DÉCADAS DEL SIGLO XX}

El propósito de este artículo es reflexionar sobre algunas posibilidades de la educación femenina durante las tres primeras décadas del siglo XX, a través de la inserción gradual de la mujer en el universo del trabajo remunerado fuera del hogar. Optamos por la metodología de investigación documental con análisis cualitativo, investigando los archivos del periódico Diário dos Campos, cuya sede se encuentra em la ciudad de Ponta Grossa - Paraná. Se observó que, de manera concomitante com las profesiones tradicionalmente entendidas como aptas para las mujeres, el género femenino también enfrentó los desafíos de incursionar en occupaciones más audaces para ellas en este contexto histórico. Se concluye que el periódico Diário dos Campos promovió la circulación de diversas noticias y reportajes que señalaban las oportunidades de la educación femenina articuladas con el mundo laboral, posibilitando no solo la formación profesional sino también social y humana.

Palavras clave: formación femenina; educación de la mujer; género femenino.

\section{Introdução}

As possibilidades de formação para o gênero feminino incluem vários espaços sociais, além dos ambientes educacionais institucionalizados. No entanto, durante muito tempo, nem todos esses espaços foram considerados adequados para a livre circulação das mulheres. A partir desse pensamento, indica-se o objetivo deste artigo, que é o de refletir sobre as possibilidades de formação das mulheres, a partir das gradativas inserções delas nos mais variados setores do mundo do trabalho, especialmente nas primeiras décadas do século XX.

Com esse fim, realizou-se uma pesquisa de abordagem qualitativa e de cunho documental nos arquivos do jornal Diário dos Campos, um periódico fundado em 1907 inicialmente com o nome de $O$ Progresso, na cidade de Ponta Grossa, interior do estado do Paraná. Essa pesquisa pautou-se na análise de todos os artigos, propagandas, entrevistas, anúncios e demais materiais textuais e imagéticos que se destinavam ou abordavam algum aspecto relacionado às mulheres durante o período indicado. Após a coleta dos dados, observouse o grande volume de menções e referências que envolviam o gênero feminino e o campo do trabalho remunerado, originando, assim, a elaboração deste artigo, especialmente a partir da compreensão sobre as possibilidades de formação feminina relacionadas à inserção no universo laboral.

A pesquisa referente ao período de 1907 a 1924 foi realizada no acervo digitalizado do referido periódico, o qual encontra-se na Casa da Memória, em Ponta Grossa. Já as fontes referentes ao período da década de 1930 foram acessadas diretamente nos arquivos físicos que se encontram no Museu Campos Gerais, também localizado em Ponta Grossa, Paraná.

$O$ recorte temporal da pesquisa concentrouse nas três primeiras décadas do século XX devido ao fato de este período constituir-se por muitas mudanças nos cenários mundial e nacional, assim como para Ponta Grossa, tendo as mulheres um papel de grande protagonismo nesse contexto histórico. Nesse sentido, citamse alguns desses acontecimentos que marcaram o período em questão, como a Primeira Guerra Mundial, de 1914 a 1918; a Revolução Russa, em 1917; a Semana de Arte Moderna, em 1922; a quebra da Bolsa de Valores de Nova Iorque, em 1929; a Revolução de 1930, que co- 
loca Getúlio Vargas no poder; o direito ao voto feminino no Brasil, em 1932; o Estado Novo, em 1937, entre outros inúmeros acontecimentos relevantes. Sobre esses aspectos que influenciaram novas compreensões sociais acerca do gênero feminino, Santos (2011, p. 149) aponta que em seus estudos constatou que:

[...] os artigos sobre o trabalho feminino fora do âmbito doméstico e sobre sua atuação no campo da política continham elementos que permitiram perceber um movimento de negociação entre os valores mais estabilizados socialmente e aqueles próximos de uma perspectiva moderna, revelando que a própria ideia de emancipação feminina já não podia ser negada e que, de modo crescente, ia tomando as páginas dos periódicos analisados.

Em nossa pesquisa, os exemplares do jornal Diário dos Campos também convergem para os mesmos aspectos indicados por Santos (2011), e a questão da emancipação feminina, promovida por meio do acesso aos estudos e ao universo do trabalho, foi frequente. Constatamos que as mulheres, além de já atuarem em áreas consideradas adequadas para o gênero feminino, como a docência das primeiras letras e as atividades relacionadas ao ambiente doméstico, também iniciavam a inserção em campos tradicionalmente masculinos, como a Medicina, a carreira militar, os cargos diretivos, entre outros, conforme abordaremos na sequência. Essa gama de possibilidades de atuação feminina é problematizada por Trindade (1996, p. 16), uma vez que:

[...] entre a dona de casa e mãe de família, concepção ideal que a sociedade de então veicula, e a meretriz socialmente desqualificada, vai-se encontrar um sem-número de mulheres empenhadas nas mais variadas atividades e situações, do lazer ao trabalho e do trabalho à marginalidade. Elas são sensíveis aos momentos de abertura que a sociedade lhes concede e cautelosas às possibilidades de fechamento.

Assim, para fundamentar a análise proposta neste artigo, fez-se uso das contribuições de algumas autoras que problematizam as questões de gênero como Freitas (2011), Telles (2015),
Scott (1995), Perrot (1998), além dos conceitos de capital e campo, cunhados por Bourdieu (1989, 2004, 2008, 2013).

\section{As relações entre as mulheres e o trabalho: possibilidades de formação profissional, social e humana}

As mulheres, historicamente, estiveram associadas à maternidade, aos afazeres domésticos e às atividades relacionadas ao cuidado de pessoas, especialmente no lar, mas também em hospitais e outras instituições de assistência social (BOURDIEU, 2017; CAMPAGNOLI, 2020; SANTOS, 2011; SCOTT, 1995). Durante muito tempo, o trabalho realizado pelas mulheres não foi remunerado, ou então foi remunerado de forma diferente do trabalho realizado por homens. Além disso, muitas ocupações culturalmente atribuídas às mulheres foram consideradas inferiores e desprestigiadas. Sobre isso, Bourdieu (2017), na obra Dominação Masculina, reflete sobre essas questões, explicando que:

Esse trabalho doméstico passa, em sua maior parte, despercebido, ou mesmo malvisto [...] e, quando ele se impõe ao olhar, é desrealizado, transferido ao plano da espiritualidade, da moral e do sentimento, o que facilita seu caráter não lucrativo e 'desinteressado'. 0 fato de que o trabalho doméstico da mulher não tenha uma retribuição em dinheiro contribui realmente para desvalorizá-lo, inclusive a seus próprios olhos, como se este tempo, não tendo valor de mercado, fosse sem importância e pudesse ser dado sem contrapartida, e sem limites, primeiro aos membros da família, e sobretudo às crianças [...], mas também externamente, em tarefas de beneficência, sobretudo para a Igreja, em instituições de caridade ou, cada vez mais, em associações ou partidos. Não raro confinadas nessas atividades não remuneradas, e pouco inclinadas, por isso, a pensar em termos de equivalência entre o trabalho e o dinheiro, as mulheres estão, muito mais que os homens, dispostas à beneficência, sobretudo religiosa ou de caridade. (BOURDIEU, 2017, p. 136-137, grifo do autor). 
Em Ponta Grossa, no ano de 1924 foi criada a Escola Normal, a primeira escola pública de formação de professores na região, após muitas reivindicações de vários setores da sociedade ponta-grossense, inclusive por meio de inúmeros artigos veiculados pelo jornal Diário dos Campos. Em um deles, publicado em 13 de setembro de 1920, o jornalista Hugo Borja dos Reis (1920), profissional da imprensa escrita bastante atuante na década em questão, reitera a urgência dessa modalidade de escola em Ponta Grossa, como forma de erradicação do analfabetismo por meio da formação de docentes para atuação na região dos Campos Gerais, da qual Ponta Grossa faz parte.

A criação desta instituição educacional pode ser compreendida como um ponto fundamental para o processo de formação feminina em Ponta Grossa, especialmente em relação à emancipação pelo trabalho, uma vez que a Escola Normal permitiu que muitas moças da região dos Campos Gerais obtivessem uma formação certificada que as habilitasse para um trabalho considerado dignificante para as mulheres da época (CAMPAGNOLI, 2020).

Assim, após o ano de 1924, percebe-se que a participação das mulheres no jornal Diário dos Campos também aumentou de forma significativa, pois as professoras da Escola Normal de Ponta Grossa demonstraram uma boa interlocução com os editores do referido periódico, por sinal, todos homens, publicando avisos e notícias sobre os mais diversos temas relacionados com as atividades desta escola. 0 excerto a seguir demonstra isso, por meio de uma notícia publicada na data de 13 de dezembro de 1932, em que o Diário dos Campos comunica sobre a Colação de Grau dos novos docentes da Escola Normal de Ponta Grossa, citando, inclusive, os nomes dos formados. É importante salientar que, no início, a Escola Normal de Ponta Grossa foi dirigida por homens, porém, já contava com algumas professoras em seu quadro docente. No entanto, com o passar do tempo, a maioria do corpo discente passou a ser composta por mulheres, assim como o coletivo de professores passou a ser composto majoritariamente por elas:

Pela educação - Colação de Grau - No salão nobre da Escola Normal, terá lugar a 17 do mês corrente, às 20 horas, a solenidade da colação dos professorandos de 1932 desse conceituado estabelecimento de ensino. A seguir, em regozijo a esse auspicioso acontecimento, será promovido grandioso sarau dançante. Os professorandos que ora se vêm galardoados por meritórios diplomas são os seguintes: Zilda Cavallin; Sezinando de Andrade; Alice Andrade; Zidah Guimarães; Humberto Schena; Diva Cunha; Maria de Souza; Mitila Rodrigues; Edla Ferraz; Mary Prado; Wanda Sá; Maria de Lourdes B. Macedo; Clementina Lona; Eudoxia Gonçalves; Herondina Gonçalves; Frieda Mayer; Nidia Del Claro; M. Lourdes Pinto; Claudinora Santos; Ruth Guasque; Placido Cardon; Hamilton Oliveira; Cacilda Bone; Azize Mattar; Marcelina Dantas; Otoniel Santos; Julita Cardoso; Izabel Andrade; Onelio Bascovia; Teodosia Stracheska; Sebastião Moura; Magdalena Kruger; Maria Clara Guimarães; Edith Novais Ribas; Lorys Jorge; Maria Zenita Teigão. (PELA EDUCAÇÃO..., 1932).

Todo esse movimento das mulheres em direção a novas perspectivas de atuação social e profissional pode ser compreendido pelo ideário republicano, o qual pregava a relevância do papel da mulher no processo de consolidação do regime em prol do progresso do Brasil (FREITAS, 2011). No jornal Diário dos Campos, durante o período analisado, as menções aos processos formativos das mulheres surgiram em uma abordagem mais tradicional, representando as mulheres nos já conhecidos papéis de mãe, esposa e professora das primeiras letras, conforme corroborado pelas pesquisas de Lopes (2017). No entanto, constataram-se outras notícias que retratavam as mulheres por um viés mais autossuficiente e emancipado. Pode-se conjecturar que essa autonomia não se deu de forma completa já nos primeiros tempos, devendo, portanto, ser compreendida como um processo longo e repleto de resistências, tensionamentos e embates, porém, alguns avanços já puderam ser visíveis. Muitas discussões giravam em torno do fato de 
as mulheres adquirirem maior liberdade de escolha, seja na educação como um todo, seja no universo do trabalho, possibilitando, assim, novos campos ${ }^{1}$ de atuação (CAMPAGNOLI, 2020; LOPES, 2017). Sobre isso, Freitas (2011, p. 38) assinala que:

Reconhecido está o lugar de destaque ocupado pelas mulheres nos discursos veiculados, principalmente pela imprensa. No entanto, essa mobilização de articulistas em cunhar as situações de conquistas por elas experienciadas, não coloca em xeque a representação feminina de coexistência entre mundo do trabalho e doméstico.

Ao problematizar as articulações das mulheres com o espaço doméstico e o trabalho fora do lar, Telles (2015, p. 66-67) pondera que “a ocupação feminina no magistério se constituiu no ponto de partida para a transição do espaço privado para o público, para a emancipação social e foi o possível, no momento histórico, em que viveram". Colaborando com esta discussão, Freitas (2011, p. 24), ao pesquisar um período histórico similar ao nosso, destaca que:

Em uma análise acerca da mulher dos primeiros decênios do século XX de maneira geral, é possível diferenciar aquelas que apresentavam comportamentos mais restritos e introspectivos daquelas que se arriscavam em transpor as barreiras do lar. Isto é, gradualmente, a roupagem romântica atrelada à mulher, que deveria apenas restringir-se ao âmbito doméstico, estava dando lugar a uma preocupação e ao desejo de ver a mulher educada, preparada para enfrentar uma vida social mais ampla, ainda que restrita a algumas atividades.

0 exposto anterior também foi observado em nossa pesquisa. Dessa forma, pode-se compreender as dinâmicas de formação feminina como processos que foram se desenvolvendo a partir do aproveitamento de todas as oportunidades que surgiam. Sobre isso, Perrot (1998, p. 37) explica que:

1 De acordo com Bourdieu (2013), o conceito de campo pode ser compreendido como um espaço social específico em que os agentes, segundo sua denominação para os indivíduos, convivem, dialogam, enfrentam-se, entre outras ações possíveis.
No século XIX, as mulheres se mexem, viajam. Migram quase tanto quanto os homens, atraídas pelo mercado de trabalho das cidades, onde acham emprego principalmente como empregadas domésticas. [...]. Existem lugares praticamente proibidos às mulheres - políticos, judiciários, intelectuais, e até esportivos... -, e outros que lhes são quase exclusivamente reservados - lavanderias, grandes magazines, salões de chá...

A partir do excerto anterior, pode-se perceber que os espaços e lugares considerados adequados para as mulheres estavam bem demarcados, tanto no ambiente privado quanto no público. No entanto, esses limites foram, pouco a pouco, sendo tensionados. Especificamente na região de Ponta Grossa, conforme já expusemos, as chamadas professoras normalistas conquistaram, a partir da criação da Escola Normal no município, um espaço legitimado de atuação pública, ou seja, um novo campo, e o jornal Diário dos Campos mostrou-se como um importante parceiro na divulgação das atividades dessas professoras. Além disso, o referido periódico colaborou para que os anúncios de professoras que lecionavam em suas próprias residências também pudessem ser lidos por muitos indivíduos. Um exemplo disso é um artigo sobre a formatura promovida pela Escola Cosmopolita, salientando o nome de sua diretora, a professora Tharcylla Chapout, nome feminino bastante recorrente no jornal Diário dos Campos, demonstrando a continuidade e desenvolvimento das atividades educacionais das mulheres na área de abrangência do periódico. Trazia o referido anúncio: "Pela educação - Terá lugar, no Salão Nobre, exames dos alunos da Escola 'Cosmopolita'. Os alunos desta escola, dirigidos pela ilustrada professora Tharcylla Chapout, lograram obter bom êxito em seus exames". (PELA EDUCAÇÃO..., 1932).

Dessa forma, como a exemplo da professora Tharcylla Chapout, muitas outras docentes que lecionavam em seus próprios domicílios faziam uso do Diário dos Campos para difundir suas ações profissionais. A questão sobre essas mulheres que exerciam atividades de ensino em 
suas próprias casas nos permite problematizar que, nessas situações, além de professoras, elas também atuavam como gestoras educacionais, selecionando os conteúdos a serem ministrados, organizando horários e turmas de alunos, entre outras ações que envolvem um planejamento pedagógico. No entanto, com o tempo, as mulheres também passaram a atuar na gestão educacional das escolas públicas que eram criadas neste contexto na cidade de Ponta Grossa. Assim, sobre a relação das mulheres com a gestão educacional, pode-se constatar que elas estiveram bastante presentes na organização e nas definições desses quesitos, especialmente na década de 1930, como demonstra a publicação do Diário dos Campos, na qual a diretora do Grupo Escolar Senador Corrêa, a senhora Myrian de França Souza (1933) assina um comunicado aos pais dos alunos da referida escola. É importante salientar que o Grupo Escola Senador Corrêa foi o primeiro grupo escolar criado em Ponta Grossa. Além disso, é importante enfatizar a relevância desta notícia, uma vez que, até então, era comum somente os homens ocuparem postos de liderança, inclusive na área educacional (CAMPAGNOLI, 2020):

Grupo Escolar 'Senador Corrêa' - Aviso aos srs. pais que a matrícula para as diversas classes deste grupo, acha-se aberta desde o dia 6 do corrente mês, das 12 horas em diante, [...], de acordo com o novo Regulamento em vigor. Ponta Grossa, 2 de fevereiro de 1933. A diretora: Myriam de França Souza. (SOUZA, 1933).

Em relação à questão de as mulheres ascenderem aos cargos de chefia nos mais variados setores do mundo do trabalho, Rabelo e Martins (2006) problematizam que, durante muito tempo, às mulheres foram negados os campos de decisões, assim como o poder de optar pelo que mais as agradasse, além do trabalho remunerado fora do lar de modo geral. Especificamente sobre a gestão educacional e os cargos diretivos, essas autoras explicam que:

[...] [no início] a condução da educação não era exercida pelas mulheres, elas apenas lecionavam. A estruturação da mesma, os cargos ad- ministrativos e de liderança, eram geridos pelos homens. Dessa forma, havia um grande controle sobre a atuação das professoras, inclusive sobre sua sexualidade. A escola continuava relegando a mulher a um plano secundário, perpetuando a submissão existente na sociedade patriarcal. (RABELO; MARTINS, 2006, p. 6172).

Assim sendo, além da possibilidade de exercer o cargo de diretora, especialmente para aquelas professoras que se formavam na Escola Normal, ou seja, que tinham uma formação formal como docentes, formação essa bastante valorizada no contexto das primeiras décadas do século $\mathrm{XX}$, constituindo-se, portanto, em capital cultural $^{2}$ na forma institucionalizada, as mulheres foram se firmando como professoras de outras áreas do conhecimento, como a música, a pintura, a datilografia, entre outros. Muitos anúncios com essas modalidades de ensino, conduzidas por mulheres, foram publicados no jornal Diário dos Campos durante o período analisado. Em um desses anúncios, uma professora, sobre a qual não se cita o nome, oferece aulas de "piano, bordado à mão e à máquina, pintura americana e outros trabalhos" (PROFESSORA, 1921).

Sobre essa modalidade de anúncio, podemos pressupor que eles se endereçassem exclusivamente às mulheres, uma vez que muitos deles, a exemplo das aulas de bordado, relacionavam-

2 O conceito de capital, de acordo com Pierre Bourdieu (1989, $2004,2008)$, pode ser classificado a partir de quatro subtipos, a saber: a) capital cultural; b) capital econômico; c) capital social; d) capital simbólico. 0 capital cultural ainda pode ser dividido em outros três subtipos, classificando-se em: objetivado, incorporado e institucionalizado. Assim, o capital cultural objetivado refere-se a materiais concretos como livros, obras de arte, mapas, entre outros objetos que possam favorecer a aquisição do conhecimento. Já o capital cultural incorporado diz respeito àquilo que o indivíduo se torna a partir do contato com os conhecimentos construídos pela humanidade, podendo ser representado, por exemplo, por seu modo de falar, seus gestos, suas posturas ou suas escolhas. 0 capital cultural institucionalizado remete aos títulos escolares e acadêmicos obtidos por meio de formação educacional formal. 0 capital econômico pode ser representado por objetos de valor, imóveis, carros, dinheiro em espécie, joias, entre outros. 0 capital social refere-se aos contatos, amizades e demais vínculos sociais entre os agentes. Por fim, o capital simbólico remete à ideia de honra, respeito, reconhecimento, influência e notoriedade de um indivíduo em um dado grupo social. 
se aos já citados trabalhos domésticos, culturalmente endereçados às representantes do gênero feminino. Essa análise nos permite refletir que, se por um lado as mulheres estavam tendo maiores chances de formação por meio do trabalho remunerado, sendo professoras, por exemplo, por outro, elas ainda viviam em ambientes sociais contraditórios, pois muitas das oportunidades de formação que para elas se destinavam ainda estavam impregnadas das representações que remetiam às mulheres que se dedicavam aos afazeres domésticos e ao espaço privado (PERROT, 1998). Desse modo, observa-se um movimento contraditório, típico de transições e momentos de mudanças sociais, em que as mulheres ora buscavam novos desafios, ora preocupavam-se em dedicar-se aos afazeres domésticos por meio da aquisição de conhecimentos específicos (CAMPAGNOLI, 2020).

Nesse sentido, nossa pesquisa também constatou outro exemplo de demarcação da presença feminina nos campos de trabalho por meio de investimentos na aquisição de capital cultural. Trata-se das professoras de instrumentos musicais e de idiomas que ofereciam seus serviços profissionais por meio de anúncios publicados no jornal Diário dos Campos. Uma dessas mulheres apresentavase como Madame Blanche Lapalu (1921), e na edição de 19 de maio de 1921 oferecia aulas de piano, solfejo e francês. Esta professora fazia questão de sublinhar que era "diplomada pela Universidade da França”, fazendo referência ao capital cultural institucionalizado, por meio de sua formação acadêmica em Música.

Outras duas conhecidas professoras de ensino da língua francesa também faziam uso recorrente do jornal Diário dos Campos para anunciar suas aulas; eram elas as senhoras Leonor Tellier e Lygia Pinheiro Machado, e um desses anúncio foi publicado na edição de 11 de agosto de 1933 (AULAS..., 1933). Aqui, mais uma vez, constata-se o capital cultural adquirido sendo utilizado como meio de alavancar as possibilidades de formação feminina.
É interessante notar que, via de regra, muitos desses anúncios não traziam os nomes das mulheres, apenas seus contatos. Esse detalhe pode ser compreendido a partir do contexto histórico abordado, período em que os nomes das mulheres ainda estavam associados à presença masculina de seus convívios, como os pais ou maridos, raramente surgindo sozinhas de modo autônomo, sem a tutela masculina (BOURDIEU, 2017; PERROT, 1998).

Ainda em relação à formação do gênero feminino vinculada às profissões tradicionalmente atribuídas às mulheres, os campos da costura e da alta costura também estiveram entre os anúncios que circularam pelo jornal Diário dos Campos, com destaque para as mulheres que faziam menção aos domínios da chamada "Alta Costura". Como exemplo, citase o anúncio publicado em 27 de novembro de 1932 (MODISTA, 1932), em que a senhora apresentada pelo periódico como Madame Olinda Renault enfatizava que era diplomada em Montevidéu, Uruguai, ressaltando, assim, a posse de capital cultural institucionalizado em uma área específica. Para problematizar as diferenças do capital simbólico entre a costura e a alta costura, assim como os impactos dessas classificações na disputa pelos campos sociais entre as mulheres, são interessantes as explicações de Bourdieu (1983, p. 2) sobre as estratégias que os agentes desenvolvem em busca de reconhecimento social e de valorização de seus conhecimentos:

Começarei descrevendo muito rapidamente a estrutura do campo de produção da alta costura. Chamo de campo um espaço de jogo, um campo de relações objetivas entre indivíduos ou instituições que competem por um mesmo objeto. Neste campo particular que é o campo da alta costura, os dominantes são aqueles que detêm em maior grau o poder de constituir objetos raros pelo procedimento da 'griffe'; aqueles cuja 'griffe' tem o maior preço. Num campo, e esta é a lei geral dos campos, os detentores da posição dominante, os que têm maior capital específico, se opõem por uma série de meios aos entrantes (emprego de propósito esta metáfora emprestada da economia), recém-chegados, 
chegados-tarde, arrivistas que chegaram sem possuir muito capital específico.

Nesse sentido, em relação à formação feminina por meio do trabalho, o jornal Diário dos Campos também demonstrou que elas estavam presentes no campo da Medicina, território dominado durante longo tempo pelos homens. No ano de 1923, muitos anúncios mencionaram as indicações da chamada "Dra. Noemy Valle Rocha" sobre o "Elixir de Nogueira", um medicamente utilizado no tratamento da sífilis, doença bacteriana que preocupava as autoridades sanitárias da época (DRA. NOEMY..., 1923). Sobre as notas acerca da "Dra. Noemy", é interessante refletir sobre o capital simbólico que esta mulher teria, a ponto de estar legitimada para indicar algum tratamento para uma doença tão grave como a sífilis era nesse contexto histórico (CAMPAGNOLI, 2020). Além disso, deve-se ressaltar que a primeira médica somente começará a atuar em Ponta Grossa nos anos de 1950, ou seja, após nosso recorte temporal (CHAVES, 2001, 2006, 2011). Aqui, podemos compreender a relevância da circulação de um nome feminino associado a um campo eminentemente masculino como a Medicina, podendo sugerir a ideia de que, em outros lugares, algumas mulheres estavam adentrando espaços até então inóspitos para elas, rompendo, assim, barreiras sociais tidas como intransponíveis para o gênero feminino. A indicação da "Dra. Noemy" dizia: “[...] Atesto que o preparado Elixir de Nogueira, do farmacêutico químico João da Silva Silveira, é um ótimo depurativo, que tenho usado na minha clínica, com resultados satisfatórios, nas afecções de origem sifilítica. [...]". (DRA. NOEMY..., 1923).

Em relação à problematização das mulheres e o trabalho como médicas, Rago (2000, p. 204) pondera que “[...] em meados do século XIX, a oposição às mulheres que optavam pela medicina era muito maior do que aquela feita em relação às profissões de menor prestígio como a enfermagem e o magistério". Nesse sentido, podemos compreender a relevância de o nome de uma médica estar circulando no jornal Diário dos Campos na década de 1920, especialmente em uma cidade do interior e tradicionalista como Ponta Grossa.

Dessa forma, Rago (2000), ao discutir os percalços pelos quais as mulheres passaram até conseguirem lograr êxito e adquirir o passaporte que as habilitasse a frequentar o curso de Medicina, ressalta a trajetória de uma das primeiras médicas brasileiras, a senhora Maria Augusta Generoso Estrela, carioca e detentora de capital econômico e social, os quais possibilitaram que seu sonho de se formar médica fosse realizado. Segundo Rago (2000), Maria Augusta convenceu seu pai, o senhor Albino Generoso Estrela, a apoiá-la para que conseguisse cursar Medicina nos Estados Unidos, algo bastante ousado para uma moça dessa época.

Além da propaganda do "Elixir" indicado pela "Doutora Noemy", o jornal Diário dos Campos também publicou outras notícias sobre mulheres envolvidas com o campo da saúde, sinalizando que as dinâmicas que apontavam apenas as profissões tradicionais e relacionadas ao universo doméstico para as mulheres, que até então eram correntes, estavam sendo modificadas, conforme também apontado por Martins (2004). Em uma dessas notícias, há a menção a uma médica que participou do concurso da "Diretoria de Saúde do Ministério da Guerra" no Rio de Janeiro (UMA MULHER..., 1933). Além de pretender atuar como médica, essa mulher também intencionava fazer parte do corpo médico militar, algo duplamente inusitado para uma mulher no contexto histórico tratado. Essa mulher chamava-se Olga Gervasia Cavalcanti Vieira e foi apresentada pelo Diário dos Campos como "doutora". Essa reportagem representa um grande avanço das lutas femininas por novos espaços sociais por meio do trabalho e da formação específica em uma área do conhecimento, novamente indicando o papel fundamental do capital cultural institucionalizado, possibilitando a inserção feminina em campos em que as mulheres ainda 
eram forasteiras. A referida notícia estampava a novidade: "A dra. em Medicina - Olga Gervasia Cavalcanti Vieira - inscreveu-se no concurso aberto na Diretoria de Saúde do Ministério da Guerra, para matrícula na Escola de Saúde do Exército. Sendo deferido, teremos brevemente a primeira mulher Tenente Médico em serviço do Exército" (UMA MULHER..., 1933).

Em outra publicação do Diário dos Campos sobre a atuação de uma médica, o periódico veiculou, na edição de 24 de março de 1933 (UMA PALESTRA..., 1933), uma entrevista com uma famosa psiquiatra que atuava nesse período e que se encontrava na cidade de Castro, próxima a Ponta Grossa. Esta médica chamava-se Madame Marozzine. Nesta entrevista, o Diário dos Campos enfatizava que os diagnósticos e tratamentos conduzidos pela doutora Marozzine estavam pautados nos princípios da ciência, ressaltando que sua postura profissional estava fundamentada em uma formação institucionalizada, conforme demonstra a transcrição da publicação, que atesta: “[...] visita a nossa redação a renomada psiquiatra Madame Marozzine. [...]. [ela] não é uma cartomante vulgar. Seu trabalho tem fundamento científico. [...]. Mostrou-nos documentos importantes, que atestam a sua proficiência. [...]. (UMA PALESTRA..., 1933).

A valorização do investimento em capital cultural institucionalizado também pode ser verificada na edição de 11 de dezembro de 1923, na qual o Diário dos Campos publicou a notícia de que a "senhorita Vicentina de Mello Cunha, dileta filha do sr. Irineo Cunha, concluiu com distinção o seu curso de Farmácia em São Paulo" (FARMACÊUTICA, 1923). Essa nota mostra-se importante, pois, conforme já afirmamos, no contexto das primeiras décadas do século XX não era comum observar-se mulheres com formação superior, ainda mais em cursos tradicionais da área da saúde, uma vez que, como em 1923 Ponta Grossa ainda não contava com qualquer instituição de Ensino Superior, quem desejasse obter esse tipo de formação deveria se deslocar para outras re- giões, a exemplo da senhorita Vicentina, que concluiu seu curso em São Paulo. Além disso, devemos conjecturar que residir em outra cidade com o intuito de estudar constitui-se, até os dias atuais, em situação que requer razoável capital econômico para tal feito e, no contexto analisado, deve-se também lembrar que para uma representante do gênero feminino, essa situação tornava-se ainda mais delicada (CAMPAGNOLI, 2020).

O campo do Direito também foi palco de acontecimentos que envolveram as mulheres e que foram retratados pelas páginas do jornal Diário dos Campos. Em uma dessas reportagens, veiculada em 25 de julho de 1932, uma mulher chamada pelo referido periódico como "Doutora Walkyria Moreira da Silva Naked, conhecida causídica ${ }^{3}$ e revolucionária" (A DRA. WALKÍRIA..., 1932), foi noticiada como a comandante de um batalhão no estado de São Paulo. Assim como as notas sobre a inserção das mulheres nos campos militar e da Medicina, a reportagem sobre uma mulher ser advogada e também estar no comando de uma frente militar nos chamou muita a atenção e sinaliza o contexto de lutas das mulheres por novos espaços no mundo do trabalho, assim como assinala a relevância da formação educacional e profissional dessas mulheres, ou seja, do acúmulo de capital cultural em suas diferentes modalidades como estratégia de disputa por espaços. Assim como as outras notícias, essa aqui também confirma a ideia de que os limites impostos às mulheres estavam sendo questionados e os avanços, mesmo que lentos, estavam ocorrendo.

O jornal Diário dos Campos ainda apresentou outras reportagens sobre as mulheres e sua inserção no campo militar, como a notícia bastante impactante para a época, que comunicava que uma moça de 17 anos ocupou o posto de sargento durante alguns dias no Batalhão João Pessoa, vestida com roupas masculinas (SENSACIONAL!, 1932). Ainda segundo a referida notícia, essa jovem cortou os cabelos, fugiu de

3 Causídica refere-se à profissão de advogada. 
casa, utilizou os documentos do irmão e apresentou-se ao quartel, permanecendo lá e participando de todas as atividades de treinamento militar até o momento em que foi descoberta. Segue a transcrição da notícia:

[...] O fato, realmente sensacional, que vamos narrar em seguida [...] é mais uma prova eloquente de que o feminismo cada vez mais se aproxima das possibilidades de vitória. 0 caso não é inédito em algumas partes do mundo, mas o é para a nossa capital. [...]. Desde sábado pela manhã que fazia parte como sargento do Batalhão João Pessoa, uma senhorita de 17 anos de idade, que ali se apresentara em trajes masculinos, sendo alistada e graduada no posto de sargento depois de mostrar habilidades nos exercícios militares que se realizou em conjunto. Quem é a heroína? Trata-se da senhorita Mirgueta Gonçalves de Oliveira, filha do sr. Benedicto Gonçalves de Oliveira, conhecido comerciante na cidade. [...]. (SENSACIONAL!, 1932).

O caso da senhorita Mirgueta Gonçalves de Oliveira é muito similar à lenda da guerreira chinesa Mulan, transformada em obra cinematográfica pela Walt Disney Animation Studos (MULAN, 2020). Nesta narrativa, a jovem Mulan, moça que domina as artes militares e o manejo de espadas, é impedida, por ser mulher, de entrar para a carreira militar. No entanto, inconformada com as barreiras impostas pelas questões de gênero, Mulan veste-se com os trajes militares de seu pai, disfarça-se de homem e apresenta-se ao quartel como soldado, sendo, após muitos contratempos, reconhecida como uma guerreira notável (MULAN, 2020). Perrot (1998, p. 136-137) colabora com este debate, explicando que "o serviço militar era considerado um equivalente da maternidade, o que justificava a isenção das mulheres". Sobre isso, D’Araujo (2003, p. 3) também esclarece que:

Tradicionalmente, a vida militar tem sido associada a risco, alta mobilidade geográfica, separação temporária da família, necessidade de praticar a violência, exposição a perigos, treinamentos intensivos, disciplina férrea, exercícios físicos pesados, solidez moral e obediência profissional acima de qualquer direito ou dever pessoal.
Dessa forma, Perrot (1998, p. 137) confirma essas impressões e acrescenta que "a profissionalização e a relativa feminização dos exércitos modernos não abolem representações de longa duração", explicando as resistências a que as mulheres ainda estão expostas nos movimentos de inserção em novas profissões, além das perspectivas tradicionais de atuação para elas. Sobre isso, D’Araújo (2003, p. 4) acrescenta que:

Na década de 1980 [ou seja, algumas décadas após nosso recorte temporal] as portas da caserna foram abertas para as mulheres. Foram aceitas inicialmente nos quadros complementares de apoio administrativo e passaram a exercer funções nos quadros de médicos, dentistas, farmacêuticos veterinários, professores, economistas, advogados e outros. Foram depois incorporadas aos quadros permanentes, não exclusivamente femininos, mas, mesmo nesta condição, não têm as mesmas oportunidades dos homens para galgar o topo da carreira. Muitos dos postos superiores estão condicionados ao exercício do comando, área ainda limitada para as mulheres. A presença da mulher em missões bélicas está associada normalmente a momentos excepcionais. Fora disso, sua imagem está mais referenciada ao lar, aos filhos, à maternidade, à ternura do que à violência e ao mundo rude e cruel da guerra ou mesmo ao mundo impessoal e frio da caserna. Há exceções como Joana D’Arc que confirmam a regra de que mulheres guerreiras são mais comuns em tempos de guerra. Por isso mesmo são normalmente figuras lendárias, temas para filmes e mitologias. Por essas percepções sua entrada na vida militar se deu de forma muito especial e no Brasil não seria diferente: são admitidas, em geral, desde que limitadas a funções administrativas. Não podem ser deslocadas para funções de combate e na Marinha de vários países estão impedidas de embarcar. As restrições vão caindo com o passar do tempo, mas ainda são objeto de intenso debate pois os desafios da luta e do combate continuam associados ao mundo masculino.

0 excerto anterior demonstra que somente nos anos de 1980, ou seja, há poucas décadas atrás, quase às portas do século XXI, é que as mulheres conquistaram um espaço formal no campo das Forças Armadas, demonstrando 
que as lutas femininas ainda se encontram em processo. Dessa forma, a circulação de notícias e reportagens nas páginas do jornal Diário dos Campos, sobre os feitos de diversas mulheres pelo mundo, especialmente em relação ao universo do trabalho, pode ser compreendida como uma forma de constituição das mentalidades e dos comportamentos das representantes do gênero feminino, isto é, como uma modalidade de formação. Como exemplo, cita-se uma propaganda sobre máquinas fotográficas, na qual duas jovens se posicionam em frente a uma senhora para fotografá-la. Este anúncio foi publicado no jornal Diário dos Campos em 26 de setembro de 1922 (MÁQUINAS..., 1922) e chama a atenção pela imagem inusitada, pois, no início dos anos de 1920, tal ação não se constituía em um ato corriqueiro para as mulheres de Ponta Grossa. No entanto, na vizinha Curitiba, capital do estado do Paraná, nos primeiros anos do século XX, portanto quase duas décadas antes da veiculação do anúncio em questão, a fotógrafa Fanny Paul Volk já atuava neste campo profissional, ainda pouco receptivo às mulheres (SIMÃO, 2010). Segundo essa autora, além de disputar o campo fotográfico enquanto forma de sustento para si e sua família, Fanny Paul Volk ainda precisou enfrentar outros desafios que estavam relacionados ao fato de ela pertencer ao gênero feminino, pois:

[...] no início do século XX, coube a Fanny conseguir existir socialmente sozinha em Curitiba carregando e administrando um estúdio fotográfico em meio a todos os elementos sociais que naquela época a inferiorizavam socialmente. $\mathrm{Ou}$ seja, era imigrante alemã, assim pela religião era considerada herege; pela conduta de ordem sexual era uma germânica, ou seja, uma mulher de moral duvidosa à sociedade receptora; somase o fato de ter se casado com o possível amante da mãe, isto - segundo o respeitável padre - que para a época valia mais que uma autoridade. Ainda, anos depois ela foi abandonada pelo marido, ficando com uma filha de dezesseis anos para terminar de criar e encaminhar para um casamento. Então, o principal desafio enfrentado por Fanny se inscreve no fato de ser uma mulher inserida em um ofício considerado masculino para época, mas que garantia o sustento de si e da sua filha. [...]. (SIMÃO, 2010, p. 138).

Desse modo, de forma gradativa e com muitos embates e tensionamentos, as mulheres foram galgando novos espaços sociais, constituindo-se como papéis preponderantes nessas conquistas o trabalho e a formação educacional. Além disso, pode-se considerar que, ao mesmo tempo em que a divulgação das ocupações femininas tradicionais estava em voga, a afirmação de outros campos não tão comuns também se fazia presente, conforme demonstrado pelos exemplos apresentados pelas mulheres que atuavam como professoras, diretoras, fotógrafas, médicas, advogadas, entre outras profissões ainda em desenvolvimento para elas no contexto abordado.

\section{Considerações Finais}

A partir de uma pesquisa qualitativa e de natureza documental desenvolvida a partir da análise dos exemplares do jornal Diário dos Campos das três primeiras décadas do século $\mathrm{XX}$, constata-se que as mulheres, as quais historicamente encontravam-se restritas às atividades domésticas sem remuneração, aos poucos foram descortinando novos horizontes, especificamente relacionados ao universo do trabalho, compreendendo-o como possibilidade de crescimento e atuação social, profissional, cultural e humana. Assim, concomitantemente à formação de cunho mais tradicional, relacionada ao universo do lar e à profissão de docente das primeiras letras, observou-se que as mulheres também estavam adentrando espaços formativos que lhes possibilitaram circular por campos não tão comuns para elas até os anos de 1930, como a Medicina, as Forças Armadas, a Advocacia, assim como campos educacionais de outras esferas como a Gestão Educacional, entre outros.

Para que esse processo fosse possível, o investimento e a aquisição das diversas modalidades de capital, especialmente o cultural, 
foram fundamentais, possibilitando a oportunidade de rompimento com o processo tradicional de formação das mulheres, voltado para o ambiente do lar. Assim, aos poucos, o gênero feminino foi ganhando espaço, por meio de uma crescente atuação pública em ambientes anteriormente frequentados, majoritariamente, por homens. No entanto, deve-se considerar que esse processo não se deu de forma linear, uma vez que o caminho feminino de formação, por intermédio do trabalho remunerado, extrapolando o espaço familiar, ainda se encontra em construção.

Dessa forma, conclui-se que o jornal Diário dos Campos, em muitas oportunidades, promoveu a circulação de notícias e reportagens sobre as relações das mulheres com o universo do trabalho, demonstrando que elas estavam dispostas a se aventurar em novos campos de atuação, formando-se não somente como profissionais, mas também como seres humanos em um novo modelo de sociedade em que as mulheres não estavam restritas apenas ao espaço doméstico.

\section{REFERÊNCIAS}

A DRA. WALKÍRIA comanda um batalhão paulista. Diário dos Campos, Ponta Grossa, PR, ano 26, s/n, s/p, 25 jul. 1932.

AULAS de francês. Diário dos Campos, Ponta Grossa, PR, ano 27, s/n, s/p, 11 ago. 1933.

BOURDIEU, P. A distinção: crítica social do julgamento. São Paulo: EDUSP; Porto Alegre: ZOUK, 2008.

BOURDIEU, P. A dominação masculina: a condição feminina e a violência simbólica. Tradução de Maria Helena Kühner. 4. ed. Rio de Janeiro: BestBolso, 2017.

BOURDIEU, P. A economia das trocas simbólicas. São Paulo: Perspectiva, 2013.

BOURDIEU, P. Escritos de educação. 6. ed. Petrópolis, RJ: Vozes, 2004.

BOURDIEU, P. 0 poder simbólico. Tradução de Fernando Tomaz. Rio de Janeiro: Bertrand Brasil, 1989.
BOURDIEU, P. Questões de sociologia. Rio de Janeiro: Marco Zero. 1983.

CAMPAGNOLI, K. R. "Da zelosa mãe e esposa à recatada professora, trabalhadora e cidadã de direitos": representações das mulheres e da sua educação no Diário dos Campos nas décadas de 1920/1930. 2020. 228 f. Dissertação (Mestrado em Educação) - Universidade Estadual de Ponta Grossa (UEPG), Ponta Grossa, PR, 2020.

CHAVES, N. B. A cidade civilizada: discursos e representações sociais no jornal "Diário dos Campos". Curitiba: Aos Quatro Ventos, 2001.

CHAVES, N. B. Entre "preceitos" e "conselhos": discursos e práticas de médicos-educadores em Ponta Grossa/PR (1931-1953). 2011. 298 f. Tese (Doutorado em Educação) - Universidade Federal do Paraná (UFPR), Curitiba, 2011.

CHAVES, N. B. Um médico, uma cidade, uma associação. In: CHAVES, N. B. (org.). Medicina em Ponta Grossa: histórias da associação médica. Ponta Grossa: Editora UEPG, 2006. p. 9-27.

D'ARAUJO, M. C. Mulheres e questões de gênero nas Forças Armadas brasileiras. Red de Seguridad y Defensa de América Latina. Santiago, 2003. Disponível em: https://www.resdal.org/ producciones-miembros/redes-03-daraujo.pdf. Acesso em: 24 maio 2019.

DRA NOEMY Valle Rocha no Rio Grande do Sul. Diário dos Campos, Ponta Grossa, PR, ano 17, s/n, s/p, 23 out. 1923.

FARMACÊUTICA. Diário dos Campos, Ponta Grossa,PR, ano 17, s/n, s/p, 11 dez. 1923.

FREITAS, D. G. de. Entre ofícios e prendas domésticas: a Escola Profissional Feminina de Curitiba (1917-1974). 2011. 133 f. Dissertação (Mestrado em Educação) - Universidade Federal do Paraná (UFPR), Curitiba, 2011.

LAPALU, Blanche. Diário dos Campos, Ponta Grossa, PR, ano 15, s/n, s/p, 19 maio 1921.

LOPES, E. M. T. Da sagrada missão pedagógica. 2. ed. Belo Horizonte: Autêntica, 2017.

MÁQUINAS e artigos fotográficos Kodak para profissionais e amadores. Diário dos Campos, Ponta Grossa, PR, ano 16, s/n, s/p, 26 set. 1922.

MARTINS, A. P. V. Visões do feminino: a medicina da mulher nos séculos XIX e XX. Rio de Janeiro: Editora FIOCRUZ, 2004.

MODISTA. Diário dos Campos, Ponta Grossa, PR, 
ano 26, s/n, s/p, 27 nov. 1932.

MULAN. Direção: Niki Caro. Burbank: Walt Disney Animation Studios, 2020.

PELA EDUCAÇÃO - colação de grau. Diário dos Campos, Ponta Grossa, PR, ano 26, s/n, s/p, 13 dez. 1932.

PERROT, M. Mulheres públicas. Tradução de Roberto Leal Ferreira. 2a reimpressão. São Paulo: Fundação Editora da UNESP, 1998.

PROFESSORA. Diário dos Campos, Ponta Grossa, PR, ano 15, s/n, s/p, 22 abr. 1921.

RABELO, A. O.; MARTINS, A. M. A mulher no magistério brasileiro: um histórico sobre a feminização do magistério. In: CONGRESSO LUSO BRASILEIRO DE HISTÓRIA DA EDUCAÇÃO, 6., 2006, Uberlândia. Anais [...]. Uberlândia, MG: FONAPER, 2006. p. 6167-6176.

RAGO, E. J. A ruptura do mundo masculino da medicina: médicas brasileiras no século XIX. Cadernos Pagu, Campinas, SP, n. 15, p. 199-225, 2000.

REIS, Hugo Borja dos. Assuntos da cidade Instrução pública. Diário dos Campos, Ponta Grossa, PR, ano 14, s/n, s/p, 13 set. 1920.

SANTOS, L. P. B. Mulheres e revistas: a dimensão educativa dos periódicos femininos Jornal das Moças, Querida e Vida Doméstica nos anos 1950. 2011. 164 f. Dissertação (Mestrado em Educação) - Universidade do Estado do Rio de Janeiro (UERJ), Rio de Janeiro, 2011.

SCOTT, J. W. Gênero: uma categoria útil de análise histórica. Educação e Realidade, Porto Alegre, v. 20, n. 2, p. 71-99, jul./dez. 1995.

SENSACIONAL! Uma moça de 17 anos era sargento do Batalhão João Pessoa - uma mistificação bem urdida e melhor realizada. Diário dos Campos, Ponta Grossa, PR, ano 26, s/n, s/p, 02 set. 1932.

SIMÃO, G. T. Fanny Paul Volk: pioneira na fotografia de estúdio em Curitiba. 2010. 457 f. Tese (Doutorado em Sociologia) - Universidade Federal do Paraná (UFPR), Curitiba, 2010.

SOUZA, Myrian de França. Grupo Escolar "Senador Corrêa". Diário dos Campos, Ponta Grossa, PR, ano 27, s/n, s/p, 03 fev. 1933.

TELLES, A. M. V. História da educação brasileira: a mulher como protagonista da educação no ideário positivista 1880-1930. 2015. 169 f. Dissertação (Mestrado em Educação) - Universidade Estadual do Oeste do Paraná (Unioeste), Cascavel, PR, 2015.

TRINDADE, E. M. de C. Clotildes ou Marias: mulheres de Curitiba na Primeira República. Curitiba: Fundação Cultural, 1996.

UMA MULHER tenente médico! Diário dos Campos, Ponta Grossa, PR, ano 27, s/n, s/p, 10 fev. 1933.

UMA PALESTRA com Mme. Marozzine. Diário dos Campos, Ponta Grossa, PR, ano 27, s/n, s/p, 24 mar. 1933. 